\title{
Workshop on Medical Ethics
}

\author{
28-30 June 1995 / 29 Muharram-1 Safar 1416 \\ International Islamic University, Islamabad, Pakistan
}

It was indeed an auspicious occasion when experts in different academic fields came together to discuss questions confronting Muslim society based on recent medical advancements. Many medical doctors, lawyers, and scholars of Islamic studies met at the International Islamic University, Islamabad, to discuss these matters. Rector Malik Meraj Khalid inaugurated the workshop. The president and prime minister of Pakistan, Farook Ahmad Khan Leghari and Benazir Bhutto, respectively, sent goodwill messages.

The legality of organ transplants and autoposies, as well as the exact determination of the actual moment of death, were the main issues of discussion. These issues were analyzed at length in order to determine whether there were substantive differences between the approach(es) of medical specialists and of Islamic studies specialists.

Muhammad Tasin, a prominent Pakistani scholar, delivered the keynote address: "The Problem of Comeal Transplantation." He examined the idea of organ transplantation and organ donation after death and found them Islamically permissible. Since the Qur'an and Sunnah contain no clear texts on these questions, he argued that the problem should be resolved through qiyās (analogy). He also argued that, in the case of genuine necessity, the dissection of corpses was lawful and cited a number of authorities to support his opinion. Based on this premise, he declared that comeal transplants were permissible. He also examined critically the arguments of scholars who consider autopsies to be unlawful.

Tasin refuted the major argument of those opposed to transplantation: Since the individual does not own his/her body, he/she cannot decide how to dispose of it after death. He cited several Qur'anic verses that describe the individual as the owner of his/her body and wealth. In general, participants were inclined to support his viewpoint and extend the lawfulness of transplantation to other human organs. They also generally agreed that an organ could be donated lawfully by a living individual if the individual's health would not be affected adversely.

The most vehement opposition came from a medical doctor, Rafiq Ahmad Ghuncha (assistant professor of anatomy, Armed Forces Medical College, Rawalpindi). He argued forcefully that a doctor's mandate was confined to the patient's reatment and not to increasing his/her life span. In support, he referred to kidney transplants, which, he said, cost on the aver- 
age about Rs 200,000 (roughly $\$ 6,250$ ). In the most successful case, a transplanted kidney scarcely survives for more than four or five years. Moreover, after the operation, a further Rps. 6000 (roughly \$US 200) is required for medication. Eventually, this means that a middle-class family must part with the accumulated resources of virtually all of the patient's close relatives. In his opinion, moreover, legalizing transplantation would encourage trade in human organs, with the result that poor and exploited segments of society would be lured into donating their organs in the hope of augmenting their income. He quoted several incidents to stress that the legalization of this practice would have disastrous consequences. All participants agreed that trade in human organs was unlawful.

The issue of performing an autopsy was considered from the legal, medical, and educational aspects. It was pointed out that such a procedure might be inevitable in a homicide investigation as well as in other cases in which the direct cause of death must be determined. The use of dissection and autopsy for educational purposes is also obvious. An overwhelming majority of the participants appreciated these facts. However, according to its proponents, it should be legalized only on the condition that respect for the human body is maintained.

The third important issue was the definition of death. Syed Sibt-i Hadi (Army Medical College, Rawalpindi) examined the medical aspect of this issue in detail. Abdur Raheem Ashraf Baloch (assistant professor, Islamic Research Institute, International Islamic University, Islamabad) discussed death from the religious permissible.

Also discussed was the permissibility of prolonging the life of an otherwise dead person via mechanical devices and whether a medical doctor should be allowed to practice euthanasia if his/her patient is in severe pain or suffering from an incurable disease. Umm Kulthum answered these questions in her paper, and participants seemed to agree with her that life and death are in the hands of God. In other words, doctors should confine their efforts to treatment at the absolute level. Any effort to increase or decrease one's life span should not be allowed, for one's life is essentially a test to which he/she is subjected by God. Therefore, any disease that is beyond the limits of medication should be dealt with in that light.

This workshop was a significant effort to examine major advancements in medicine from an Islamic perspective. Its most fascinating feature was the amicable environment maintained by scholars whose academic and ideological backgrounds vary greatly. Participants showed a willingness to consider opposing viewpoints with remarkable patience and open-mindedness, to rethink their previous positions, and to give serious consideration to other opinions. The workshop also proved the efficacy of Urdu for expressing ideas and concepts that are both complex and subtle.

Khurshid Ahmad Nadeem International Institute of Islamic Thought, Pakistan Islamabad, Pakistan 